\title{
A Rare Case of a Non-Hodgkin's Lymphoma Presented As a Single Bone Lesion
}

\author{
Gregory Tsoucalas*1,2, Theodoros G. Papaioannou ${ }^{3}$, Ismini Mainta ${ }^{1}$, Vasilios Thomaidis ${ }^{2}$ and Aliki Fiska $^{2}$ \\ ${ }^{1}$ Nuclear Medicine Department, Anticancer Hospital Saint Savvas, Greece
}

${ }^{2}$ Department of Anatomy, Democritus University of Thrace, Greece

${ }^{3}$ Department of Cardiology, University of Athens, Greece

Received: March 05, 2018; Published: March 16, 2018

*Corresponding author: Gregory Tsoucalas, Ieroloxiton 155, Agioi Anargyroi, Volos, PC. 38334, Greece, Tel: 302421078583;

Email: gregorytsoucalas@yahoo.gr

\begin{abstract}
Primary bone lymphoma depicts a 1-2\% of adult non-Hodgkin lymphomas. We report a rare case of a single bone lesion in a 28 years old female patient with her left femur afflicted. Our case aims to alert physicians upon a simple gait disturbance and mild knee pain.
\end{abstract}

Keywords: Primary bone lymphoma; Single bone lesion; Oncology; Anatomy

Abbreviations : NHL: Non-Hodgkin Lymphomas; PBL: Primary Bone Lymphoma

\section{Introduction}

Hematological malignancies present a clinical spectrum of symptomatology which ranges from no focal skeleton lesions in leukaemia to numerous lytic lesions in multiple myeloma. Reports of a primary bone lymphoma (PBL) are rather rare, accounting for less than $1-2 \%$ of adult non-Hodgkin lymphomas (NHL) [1], commonly affecting mainly femur, as well as spine and pelvis, causing dominantly localized bone pain [2]. We report a 28 years old female patient with NHL, presented as a single primary bone lesion on her left femur.

\section{Case Report}

The patient was admitted to our hospital complaining of mild bone pain in her left knee, gait disturbance and local swelling. Physical examination revealed pain while walking, induration and pain with palpation of the distal end of femur and the surrounding soft tissues, with no other signs of inflammation. No palpable lymph nodes were discovered, inguinal or elsewhere. Haematological exams included WBC: $6.7 \times 10^{9} \mathrm{~L}$, haemoglobin $14 \mathrm{~g} / \mathrm{dl}$, platelet count 294X10 ${ }^{9}$ L, ESR 1st h: 22mm, CRP: 0.98mg/dl, LDH: $152 \mathrm{U} / \mathrm{l} \mathrm{Ca}^{+2}$ : $9.7 \mathrm{mg} / \mathrm{dl}$, ALP: $86 \mathrm{U} / \mathrm{l}$. The antibody for human lymphotropic virus type-I was negative, as well as urinalysis for Bence Jones protein. Bone marrow examination revealed no abnormal cells. Bone x-ray demonstrated osteolysis of the distal third of the left femur with a slightly raised periosteum. MRI demonstrated a lobulated bone osteolytic lesion with extension to the surrounding soft tissues with a limited cortical destruction (Figure 1). Abdominal CT scan revealed several small inguinal lymph nodes with central necrosis, whereas whole body scintigraphy with Tc-99mMDP depicted an increased uptake of the radiotracer upon the anatomical region of the known lesion, with no other abnormalities of the rest of the skeleton. The biopsy was consistent with the existence of a CD-20 positive B-cell non-Hodgkin's lymphoma.

\section{Discussion}

PBL tumour represents an uncommon case in oncology, exhibiting morphologic diversity. Thus, its definition varies throughout the literature [2]. There is a debate among researchers for the role of lymph node metastases. Although some support that PBL is defined as a malignant lymphoma arising within the medullary cavity of a single bone without concurrent regional lymph node or visceral involvement [3], others accept regional existence of lymph node and/or visceral metastases, suggesting a time interval for their appearance greater than 6 months after diagnosis [4]. It is noted that age is the main predictor variable associated with survival. Thus, patients younger than 40 years have better chances for both a 5-year and overall survival [2]. Disease progression or 
relapse appears to confer a poor prognosis [1]. Pathogenesis of such as interleukin-1, PTHrP, and carcitriol produced by lymphoma bone lesions in lymphomas is unclear. Many factors are implicated, cells, which all could mediate in bone destruction.

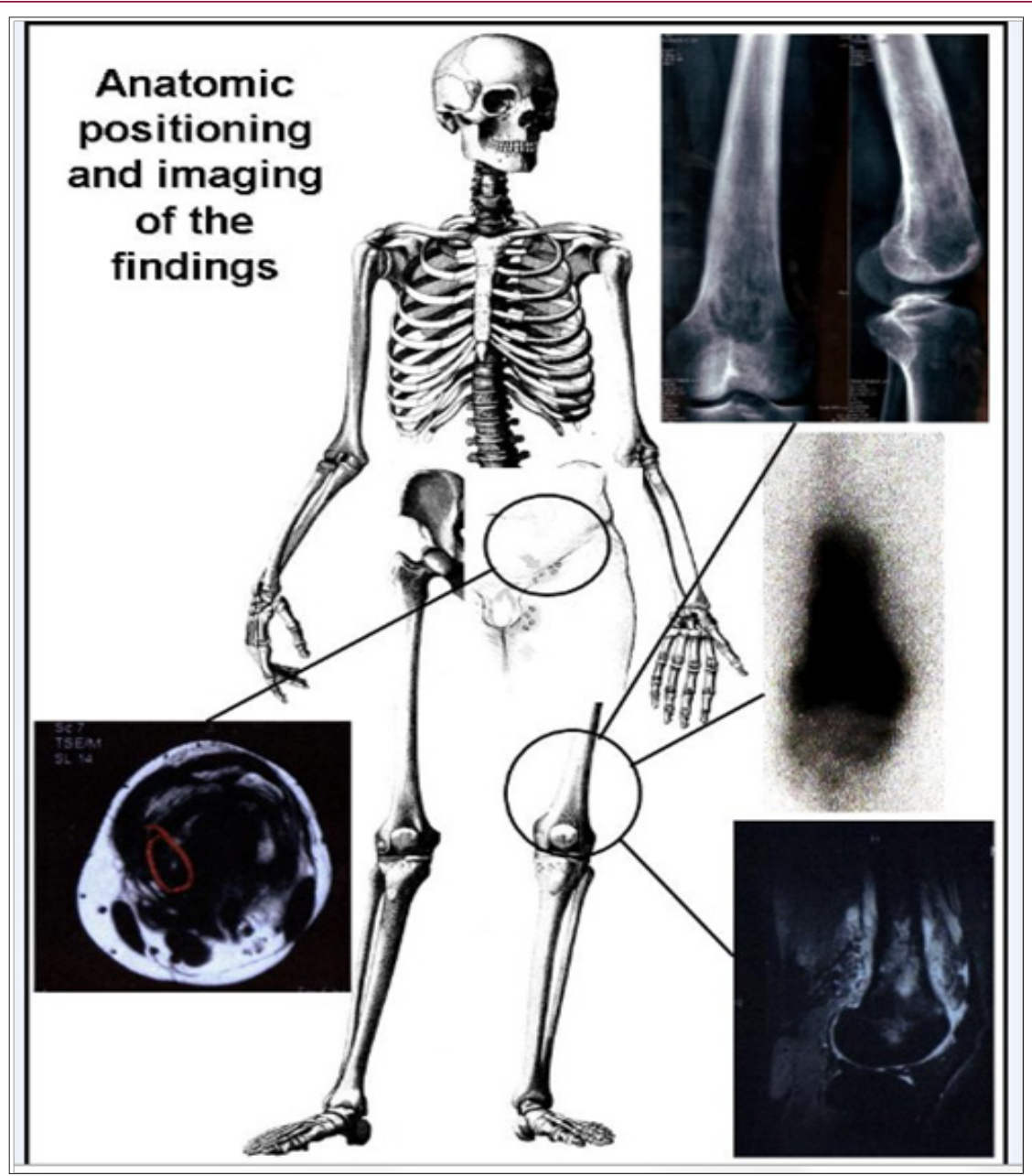

Figure 1: MRI demonstrated a lobulated bone osteolytic lesion with extension to the surrounding soft tissues with a limited cortical destruction.

Tumour activation of osteoclastic resorption of bone tissue, stimulated by cytokines, could produce tunnels penetrating the cortex, resulting to a probable soft-tissue expansion and a large mass without extensive cortical destruction [2]. The radiologic differential diagnosis should include both benign entities like osteomyelitis, and malignant entities like Hodgkin lymphoma, sarcoma, neuroblastoma and metastatic disease [5]. PBL rarity makes its optimal treatment unknown. Applied R-CHOP (Rituximab, Cyclophosphamide, Doxorubicin, Vincristine, Prednisolone) is the most common utilized chemotherapy regime, while local radiotherapy is also proposed to be applied directly upon the lesion for the prevention of pathologic fractures [1]. Surgical treatment of malignant tumours about the knee requires careful preoperative planning to achieve appropriate oncologic results and is reserved only for selected cases. Resection-arthrodesis for malignant and potentially malignant lesions about the knee using an intramedullary rod and local bone grafts could be used. However PBL's rapid disease progression, $40 \%$ to $50 \%$ overall survival at 5 years, and reports of lymphoma rapid arising in bone adjacent to metallic prostheses make surgery a debatable intervention [6-7].

\section{Conclusion}

Our case endeavours to emphasize on physicians' alertness upon a simple gait disturbance and mild knee pain. PBL may be scarcely appearing in daily practice, however it requires to be properly addressed and long term monitored.

\section{References}

1. Power DG, McVey GP, Korpanty G, Treacy A, Dervan P, et al. (2008) Primary bone lymphoma: single institution case series. Ir J Med Sci 177(3): 247-251.

2. Takasaki H, Kanamori H, Takabayashi M, Yamaji S, Koharazawa H, et al. (2006) Non-Hodgkin's Lymphoma Presenting as Multiple Bone Lesions and Hypercalcemia. Am J Hematol 81(6): 439-442.

3. Dosoretz DE, Raymond AK, Murphy GF, Doppke KP, Schiller AL, et al. (1982) Primary lymphoma of bone. The relationship of morphologic diversity to clinical behavior. Cancer 50: 1009-1014.

4. Ostrowski ML, Unni KK, Banks PM, Shives TC, Evans RG, et al. (1986) Malignant lymphoma of bone. Cancer 58(12): 2646-2655.

5. Stein ME, Kuten A, Gez E, Rosenblatt KE, Drumea K, et al. (2003) Primary lymphoma of bone--a retrospective study. Experience at the Northern Israel Oncology Center (1979-2000). Oncology 64(4): 322-327. 
6. Ashton Acton Q (2012) In: Immunoproliferative Disorders-Advances in Research and Treatment. Scholarly Editions pp. 1-54.

\section{(c) This work is licensed under Creative}

Submission Link: https://biomedres.us/submit-manuscript.php
7. Scott NW (2011) Insall \& Scott Surgery of the Knee. Elsevier Health Sciences, USA.

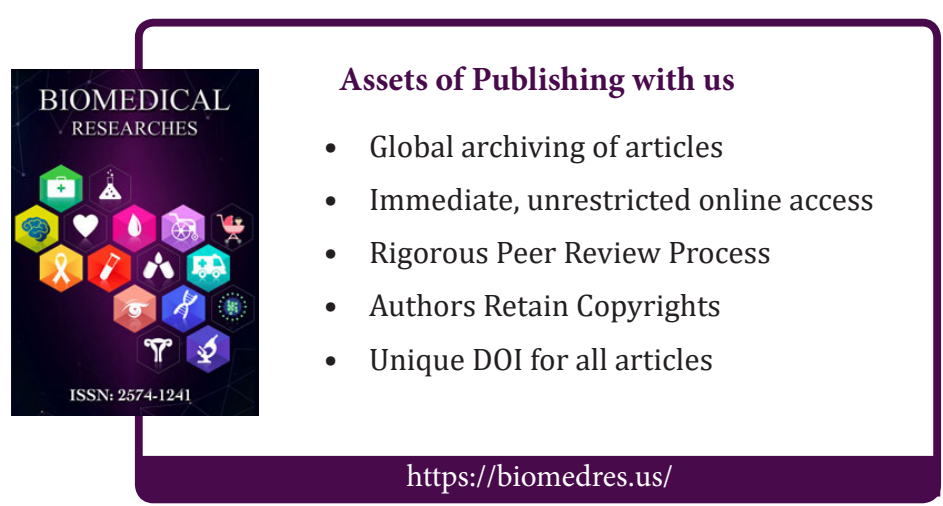

